\title{
KEDAH PASCA PERJANJIAN 1923: KEDUDUKAN ORANG MELAYU DALAM PENTADBIRAN KERAJAAN
}

\author{
Noor Ain bt Mat Noor \\ Ahmad Kamal Ariffin bin Mohd Rus
}

\begin{abstract}
This article examine the position of the Malays in the administration of Kedah after the 1923 Agreement between the state and the British. The agreement intended to delineate the relationship of both parties, which previously was ambiguous and had caused tension and discontentment. However, before the agreement was signed, Tunku Ibrahim as a Regent, laid down several conditions. This article examine whether Tunku Ibrahim's request affected the position of the Malays in the administration of Kedah. The evident indicate that during the period between 1923-1941 the administrative position of the Malays in Kedah was not substantially affected. On the other hand, certain institution were successfully strengthened. For example, the Kedah State Council with a Malay majority and not the British Advisor had the power to determine the selection and placement of administrative officials in the government. This ruling also involved the selection of British officers sent to Kedah. This period also witnessed the enabling of the Kedah government to ensure that the internal appointments were filled by local Malays. More importantly, due to the terms set by Tunku Ibrahim, the Malay language remained as the official language and the Jawi script as the official script of the Kedah government.
\end{abstract}

\section{Pengenalan}

Kemaraan penguasaan British di negeri-negeri Melayu utara pada awal abad ke-20 mempunyai motif tersirat yang sememangnya dirancang rapi. Motif tersebut lebih didorong oleh perkembangan politik serantau 
yang melibatkan persaingan kuasa antara British, Perancis dan pada isu tertentu turut membabitkan pihak Jerman. Kesungguhan British dalam memperkukuhkan pengaruhnya terhadap negeri-negeri Melayu utara telah terhasil apabila Perjanjian Bangkok ditandatangani pada 10 Mac 1909. Artikel 1 perjanjian tersebut seperti yang difahami oleh kedua pihak yang terlibat, telah menyerahkan hak pertuanan Siam terhadap Kelantan, Terengganu, Perlis dan Kedah kepada British. Perkembangan tersebut telah mencetuskan kegelisahan dan kemarahan Raja-raja Melayu kerana penyerahan itu dilakukan tanpa dirujuk mahupun dimaklumkan kepada mereka.

Dalam konteks Kedah misalnya, perjanjian itu dianggap bagai barah yang mula menyaraf ke dalam sentimen kumpulan pemerintahnya. Protes yang ditunjukkan para elit Kedah terhadap beberapa tindak tadbir Penasihat British yang pertama merupakan manifestasi daripada kemarahan terhadap cara Kedah diserahkan kepada British. Artikel ini cuba menghujahkan bahawa tindakan Tunku Ibrahim (Pemangku Raja) menegaskan permintaan tertentu sebelum Perjanjian 1923 ditandatangani telah berupaya mempertahankan kepentingan perjawatan Melayu dalam pentadbiran Kedah. Langkah yang diambil oleh Tunku Ibrahim sudah semestinya digerakkan oleh iktibar tertentu. Kedudukan Raja-raja Melayu di Negeri-negeri Melayu Bersekutu serta syarat yang diperturunkan Sultan Ibrahim, Johor, semasa menandatangani perjanjian dengan British pada tahun 1914, telah memberi ilham kepada baginda tentang bagaimana menghadapi tekanan penguasaan British yang terlalu sukar untuk dielakkan ketika itu.

\section{Termeterainya Perjanjian 1923}

Perjanjian yang ditandatangani antara Kedah dengan British pada 1 November 1923, bertitik tolak daripada konflik-konflik yang timbul di antara pentadbir Melayu Kedah dengan Penasihat British berkaitan kedudukan mereka dalam pentadbiran Kedah. Antara isu yang paling menonjol adalah berkaitan kedudukan Penasihat British dalam Majlis Mesyuarat Negeri (MMN). W. G. Maxwell yang dilantik sebagai Penasihat British yang pertama di Kedah pada tahun 1910 dikatakan bertindak melampaui batas sehingga mendatangkan kemarahan di pihak Tunku Mahmud (Presiden MMN, 1907-1914) dan ahli-ahli MMN Kedah. Kedah berpendapat bahawa Penasihat British seperti Penasihat Kewangan Siam sebelumnya hanya menasihati sultan dan MMN dalam hal ehwal kewangan sahaja. Walau bagaimanapun, Maxwell didapati bertindak lebih jauh apabila beliau telah mencampuri hal ehwal pentadbiran Kedah. 
Dalam hal ini, pembesar Melayu Kedah menentang percubaan Maxwell untuk memastikan sebarang surat rasmi Kedah kepada Pesuruhjaya Tinggi British mestilah melalui Residen Jeneral. Perkara ini dianggap oleh Kedah sebagai satu hal yang tidak perlu kerana semasa di bawah naungan Siam, semua surat-menyurat ditulis terus kepada Bangkok tanpa melalui pihak ketiga. Maxwell juga didapati telah menguruskan surat-menyurat dalam bahasa Inggeris tanpa berunding atau memaklumkan kepada MMN. Beliau dengan sengaja telah mengenepikan nama Kedah daripada alat-alat tulis rasmi dan menggunakan cop mohor sendiri yang tidak ada sifat nyata mengenai kemahkotaan Kedah. Di samping itu, Maxwell juga bertindak mengibarkan bendera Union Jack di tempat kediamannya dan ini telah menimbulkan kemarahan dalam kalangan pembesar Melayu Kedah. Beliau juga pernah memohon untuk menjadi Penolong Presiden namun ditentang hebat oleh Tunku Mahmud. ${ }^{1}$

Keadaan ini diburukkan lagi apabila Maxwell telah mengeluarkan arahan kepada ketua-ketua jabatan dan pegawai bawahan tanpa merujuk kepada MMN. Beliau juga cuba memotong wang dan elaun kerabat diraja kepada putera dan puteri yang berumur 15 tahun ke bawah. Kemuncak kepada penentangan ini, pegawai-pegawai Melayu telah mengadakan mogok dan tidak mahu bekerjasama. Dalam konflik ini, Tunku Mahmud merupakan tokoh utama yang mendalangi penentangan terhadap Maxwell. Malah beliau pernah mengancam akan meletakkan jawatan jika Maxwell tidak ditukarkan. Walau bagaimanapun, hasil tolak ansur di antara golongan Tunku Mahmud dan Penasihat British, perhubungan kedua-dua pihak dapat dibaiki. Dengan campur tangan John Anderson selaku Pesuruhjaya Tinggi British pada ketika itu, Maxwell sedia meminta maaf daripada Tunku Mahmud. ${ }^{2}$ Dengan ini, krisis di antara kedua-dua pihak mula reda.

Menjelang 1913, berlaku satu lagi krisis yang membabitkan isu Pemangku Raja di Kedah. Pada tahun tersebut, pakatan Tunku Mahmud dan ahli MMN telah berjaya mendesak British melantik Pemangku Raja disebabkan kesihatan sultan yang pada masa itu semakin terjejas. ${ }^{3}$ Walau bagaimanapun, tuntutan mereka untuk mengekalkan kedudukan Tunku Mahmud sebagai Presiden MMN diketepikan oleh British. Tunku Mahmud sebaliknya hanya dilantik sebagai Timbalan Presiden MMN manakala jawatan Presiden MMN diserahkan kepada Tunku Ibrahim (Pemangku Raja). Isu pelantikan Pemangku Raja telah mencetuskan konflik di antara pembesar Kedah dengan British. Dalam hal ini, ahli MMN menganggap dengan pelantikan Tunku Ibrahim sebagai Pemangku Raja, keahliannya dalam dewan akan gugur dan seorang ahli lain perlu dilantik. Pandangan ini dirujuk kepada 
pengisytiharan sultan pada 23 Julai 1905 apabila MMN hendak dibentuk. Pengisytiharan itu hanya menyebut keanggotaan MMN adalah terdiri daripada pegawai tinggi Melayu dan bukannya sultan.

Berdasarkan pengisytiharan tersebut, adalah jelas bahawa Pemangku Raja bukanlah pegawai kerajaan tetapi merupakan ketua negeri yang mewakili sultan dalam menjalankan pemerintahan selama sultan gering. Dengan mengambil alih tugas sultan, bererti Tunku Ibrahim diberi kuasa diraja sedangkan kedudukannya dalam MMN hanyalah sebagai penasihat sahaja. Seperkara yang membimbangkan Tunku Ibrahim, sekiranya beliau menjadi Presiden MMN, ini bererti beliau telah mengetepikan Tunku Mahmud, ayah saudaranya. Apa yang lebih penting, jika Pemangku Raja berada di luar MMN, secara langsung akan memberikan lebih kebebasan kepada MMN untuk bersidang dan berbincang. Dalam hal ini, muslihat Kedah adalah untuk memastikan Pemangku Raja berada di luar MMN supaya beliau dapat menggunakan kuasa pembatalnya jika sesuatu undang-undang yang diluluskan bertentangan dengan kepentingan umum Kedah. Dengan beradanya beliau dalam MMN bererti Pemangku Raja sudah menerima nasihat daripada Penasihat British dan bersama-sama membuat keputusan lantaran tidak mempunyai ruang lagi untuk berhelah menolaknya. ${ }^{4}$

Dalam menghadapi isu ini, Kedah telah menggunakan perkhidmatan guaman yang menjadi penasihat undang-undang Kedah iaitu Adam \& Allen di Pulau Pinang dan Charles Russel di London. ${ }^{5}$ Isu berkaitan Kedah juga cuba dibangkitkan oleh Charles Russel di Parlimen British. Seterusnya, beberapa surat telah ditulis oleh Charles Russel kepada Pejabat Tanah Jajahan dan Pejabat Setiausaha Luar British. Namun, usaha ini tidak berjaya. Begitu juga dengan usaha membawa isu ini ke Parlimen British. Walaupun berjaya tetapi tidak mendapat simpati daripada ahli-ahli dewan disebabkan British pada masa itu terlibat dalam Perang Dunia Pertama. Manakala usaha berhubung terus dengan pihak berkuasa di London juga tidak dilayan. ${ }^{6}$ Kedah akhirnya terpaksa akur dengan keputusan British yang mahu mengekalkan Tunku Ibrahim sebagai Pemangku Raja dan Presiden MMN.

Secara umumnya, dapat dilihat dalam tempoh 1909-1923, timbul banyak masalah tentang kedudukan Penasihat British dan pentadbir Melayu. Dalam hal ini, pihak British dan Kedah mempunyai kepentingan masing-masing untuk dilindungi. British mahu mengenakan kuasanya manakala Kedah mahu mempertahankan kedudukan, kuasa dan pengaruh yang dimiliki selama ini. Hakikatnya, British belum lagi menandatangani perjanjian rasmi dengan Kedah 
berkaitan hak pertuanannya terhadap Kedah. Hak British terhadap Kedah hanyalah bergantung kepada Perjanjian Bangkok pada tahun 1909 sahaja. Untuk itu, Perjanjian 1923 yang telah dimeterai pada 1 November 1923 dianggap sebagai jalan penyelesaian terhadap krisis yang timbul antara pentadbir Melayu Kedah dengan pihak British serta bagi menjelaskan lagi hubungan antara Kedah dengan British.

Perjanjian yang ditandatangani di Singapura di antara Tunku Ibrahim dengan Sir Laurence Nunns Guillemard ini telah disaksikan oleh William Peel (Penasihat British) dan A. F. Richards (Pemangku Setiausaha kepada Pesuruhjaya Tinggi) di pihak British manakala di pihak Kedah pula disaksikan oleh Syed Mansur al-Jafri (Setiausaha Kerajaan) dan Syed Mohamed Idid (Ketua Hakim Melayu). ${ }^{7}$ Kandungan perjanjian tersebut mencakupi tujuh Artikel kesemuanya. Dalam Artikel satu dan dua, penekanan diberikan terhadap hubungan di antara British dengan Kedah. Artikel satu misalnya secara jelas meletakkan Kedah sebagai Negeri Lindungan British. Manakala Artikel dua menegaskan bahawa Sultan Kedah tidak boleh berhubung dengan mana-mana kuasa asing melainkan mendapat persetujuan daripada kerajaan British.

Sementara itu, Artikel tiga dan empat pula memberi perhatian terhadap soal kedaulatan dalaman negeri Kedah. Sebagai contoh, dalam Artikel tiga, Kedah telah diberi jaminan oleh British bahawa negeri itu tidak akan dipindahkan atau disatukan dengan mana-mana negeri lain tanpa mendapat persetujuan dari Sultan Kedah. Dalam Artikel empat pula, telah ditetapkan bahawa pengganti atau pewaris takhta Sultan Kedah akan ditentukan sendiri oleh Sultan yang memerintah setelah diputuskan dalam Majlis Mesyuarat Negeri dan diterima oleh pihak British.

Perjanjian ini juga secara langsung menyelesaikan masalah pentadbiran dalaman negeri Kedah yang melibatkan pihak British. Artikel lima sebagai contoh, menyatakan bahawa Sultan Kedah akan menerima Penasihat British untuk menasihati baginda dalam hal ehwal kerajaan kecuali yang bersangkutan dengan adat Melayu dan agama Islam. Dalam Artikel enam pula, ditetapkan bahawa Sultan akan mentadbir negeri dengan bantuan Majlis Mesyuarat Negeri yang keanggotaannya terdiri daripada Sultan sebagai presiden, tiga ahli Melayu yang dipilih oleh sultan dengan persetujuan British dan Penasihat British. Sementara itu, dalam Artikel terakhir disebut dengan jelas bahawa bahasa Melayu dan tulisan Jawi akan digunakan sebagai bahasa dan tulisan rasmi dalam semua jabatan kerajaan di Kedah. ${ }^{8}$

Dalam proses menandatangani perjanjian ini, pihak Kedah sedaya upaya cuba mempertahankan kepentingan dan kedaulatan negerinya. Dalam hal ini, Pemangku Raja iaitu Tunku Ibrahim telah 
mengemukakan beberapa syarat penting sebelum perjanjian 1923 dimeterai di antara kedua-dua pihak. Antara syarat-syarat yang dikemukakan ialah Penasihat British yang hendak dihantar bertugas ke Kedah perlulah terlebih dahulu dirujuk kepada MMN dan dipersetujui oleh Pemangku Raja. Pegawai tadbir British yang hendak dihantar ke Kedah juga perlulah mendapat kelulusan daripada MMN dan bukannya Penasihat British. Pegawai tersebut akan dianggap sebagai pegawai Kedah dan dikehendaki memakai pakaian seragam putih Kedah. Walau bagaimanapun, pemakaian seragam ini tidak dikenakan kepada Penasihat British.

Selain syarat di atas, pemerintah Kedah juga berhak menukarkan seseorang pegawai British daripada perkhidmatan awam Kedah jika didapati perkhidmatannya itu tidak memuaskan atau tidak lagi dikehendaki. Bagi jawatan pegawai negeri Kedah, keutamaan akan diberikan kepada orang Melayu yang menetap di Kedah. Selain itu, MMN juga akan memilih para pelajar dari Kedah untuk dihantar melanjutkan pelajaran ke Asia Barat dan Eropah atau ke negeri-negeri lain supaya orang Melayu akan menjadi lebih cekap dalam melaksanakan pentadbiran di Kedah. Dalam hal ini, perbelanjaan para pelajar sepanjang pengajian mereka di luar negeri akan dibiayai oleh kerajaan. Tunku Ibrahim juga telah menetapkan syarat bahawa taraf pegawai Melayu dan Eropah adalah setaraf sama ada dalam aspek gaji mahupun perkhidmatan. Beliau juga mahukan Setiausaha Kerajaan dan Ketua Hakim Melayu dikekalkan keanggotaan mereka di dalam MMN. ${ }^{9}$

Berdasarkan syarat-syarat yang diutarakan ini, jelas menunjukkan bahawa Tunku Ibrahim telah berusaha untuk mengekalkan keperibadian Kedah sebagai sebuah negeri Melayu. Hasil rundingan dan tolak ansur daripada kedua-dua pihak, syarat-syarat ini telah diterima oleh British manakala kerajaan Kedah pula bersetuju dengan kandungan Perjanjian 1923. Untuk itu, dalam artikel ini, isi kandungan Perjanjian 1923 dan syarat-syarat Tunku Ibrahim yang relevan dengan kepentingan orang Melayu akan dibincangkan sama ada syarat-syarat tersebut dipatuhi ataupun tidak dalam pentadbiran Kedah pada tempoh selepas perjanjian tersebut ditandatangani.

\section{Peranan MMN Dalam Pelantikan Pegawai Tadbir Tempatan dan Eropah}

MMN Kedah yang ditubuhkan pada 1905 merupakan sebuah institusi pemerintahan penting yang dijadikan alat oleh golongan pemerintah untuk mewajarkan pentadbiran negeri. MMN mempunyai peranan yang luas termasuklah membuat undang-undang dan peraturan 
pentadbiran serta menetap dan menentukan kira-kira perbelanjaan negeri. Melalui MMN, undang-undang dan peraturan dikeluarkan untuk mengawal kehidupan rakyat. ${ }^{10}$ Pada awal penubuhannya, keanggotaan MMN Kedah adalah kecil bilangannya iaitu seramai lima orang ahli. Empat daripada ahlinya adalah terdiri daripada pegawaipegawai tinggi kerajaan Melayu manakala seorang lagi ahli ialah Penasihat British. Sementara wakil-wakil daripada kaum lain seperti Cina dan India tidak menganggotai MMN Kedah. Jumlah keanggotaan dalam MMN Kedah ini kekal sehingga tempoh selepas Perjanjian 1923 ditandatangani.

Dalam MMN Kedah, walaupun Penasihat British disenaraikan sebagai ahli, namun pihak yang menguasai MMN adalah orang Melayu yang terdiri daripada Presiden, Setiausaha Kerajaan, Ketua Hakim dan lain-lain pegawai tinggi kerajaan. Penasihat British tidak mempunyai kuasa dalam mengeluarkan sesuatu arahan dalam MMN sebaliknya kuasa tersebut adalah terletak di tangan Presiden MMN. Malah Penasihat British juga perlu merangka enakmen, minit mesyuarat dan memorandum dalam bahasa Melayu disebabkan bahasa Melayu merupakan bahasa yang digunakan dalam prosiding MMN. Terjemahan undang-undang ke dalam bahasa Inggeris hanya dibuat setelah diluluskan oleh MMN..${ }^{11}$ Sungguhpun begitu, Penasihat British berhak membuat sebarang cadangan terhadap sesuatu perkara yang dibincangkan dalam MMN. Walau bagaimanapun, kuasa untuk memutuskannya masih terletak di tangan Presiden MMN. Dalam hal ini, dapat dilihat bahawa personaliti utama yang paling menonjol dalam MMN adalah Presiden MMN itu sendiri. Tunku Ibrahim yang memegang jawatan sebagai Presiden MMN dari tahun 1914-1934 dilihat sebagai individu yang paling berpengaruh dan memainkan peranan yang penting dalam memastikan MMN Kedah terus dikuasai keahlian Melayu.

Salah satu syarat yang ditetapkan oleh Tunku Ibrahim sebelum termeterainya Perjanjian 1923 adalah berkaitan dengan pelantikan pegawai British yang perlu dirujuk kepada MMN terlebih dahulu dan bukannya Penasihat British. Di samping itu, pengisian jawatan pegawai tadbir juga diberi keutamaan kepada orang Melayu yang dilahirkan di Kedah. ${ }^{12}$ Dalam hal ini, dapat dilihat bahawa Tunku Ibrahim cuba memastikan pegawai yang dilantik di Kedah diberi keutamaan kepada orang Melayu dan mahu meminimumkan sebanyak mungkin bilangan pegawai Eropah di Kedah.

Dalam tempoh Tunku Ibrahim menjadi Pemangku Raja, beliau memandang serius terhadap pelantikan pegawai-pegawai Eropah yang ditugaskan ke Kedah. Bagi menggalakkan pegawai Eropah memahami 
adat resam tempatan yang secara langsung akan melicinkan pentadbirannya, elaun-elaun akan diberikan kepada mereka yang dapat menguasai bahasa Melayu dan tulisan Jawi. ${ }^{13}$ Dalam memelihara kepentingan Kedah, Tunku Ibrahim telah memastikan pegawai atasan yang terpilih terdiri daripada mereka yang taat setia kepada Kedah. Sekiranya terdapat pegawai yang hendak dilantik tetapi tidak dikenali beliau, maka pegawai tersebut ditemuduga terlebih dahulu dan setelah diperkenankan, pegawai itu perlulah menandatangani surat sumpah taat setia.

Tunku Ibrahim pernah menolak cadangan Penasihat British membawa masuk pegawai-pegawai dari NNMB yang mempunyai kelulusan tinggi untuk berkhidmat di Kedah. ${ }^{14}$ Bagi memastikan pegawai Melayu tidak tunduk kepada British, para pegawai ini diberikan latihan yang secukupnya dengan menghantar mereka mengikuti kursus dalam perkhidmatan. Malahan tindak tanduk mereka di luar pejabat juga diperhatikan. Mereka tidak dibenarkan bersantai di kedai kopi atau di rumah rehat yang sering dikunjungi oleh pegawai British melainkan berurusan penting. ${ }^{15}$

Pada masa yang sama, kerabat diraja juga dilarang berkahwin dengan wanita Eropah dan jika peraturan ini dilanggar, keistimewaan mereka sebagai kerabat diraja akan digugurkan. Bagi pelajar Kedah yang berada di luar negara dan berasal daripada keturunan rakyat biasa, sekiranya mereka berkahwin dengan wanita Eropah, mereka tidak akan diberi pekerjaan di Kedah. Tindakan ini dilaksanakan ini dianggap sebagai suatu usaha bagi mengekalkan Kedah sebagai sebuah negeri Melayu serta untuk mengekalkan keperibadian elit-elit Kedah. ${ }^{16}$ Malah dalam mesyuarat MMN sendiri, Tunku Ibrahim terlibat secara langsung dalam perbincangan berkaitan perjawatan orang Melayu dan British dalam pentadbiran Kedah. Dalam hal ini, ahli-ahli MMN yang diketuai oleh Tunku Ibrahim memainkan peranan yang penting dalam membuat sebarang keputusan berhubung pelantikan pegawai tempatan dan Eropah di Kedah. Dalam soal pengambilan kakitangan Eropah misalnya, rujukan perlulah dibuat kepada Pemangku Raja dan MMN terlebih dahulu sebelum diterima masuk ke dalam perkhidmatan awam Kedah. Hal ini dapat dilihat apabila Pemangku Raja Kedah dengan kebenaran MMN dan Pesuruhjaya Tinggi telah melantik George Bannerman Kellagher sebagai Hakim Eropah di Mahkamah Tinggi berkuatkuasa pada 26 Julai 1933. Beliau menggantikan Justice $W$. H. Dinsmore yang telah bersara daripada jawatannya. ${ }^{17}$ Pemangku Raja dengan kebenaran MMN juga telah meluluskan pelantikan Justice John Christopher Cobbett yang sebelum ini menjadi hakim di Pulau Pinang dan dilantik sebagai hakim bagi 
Mahkamah Rayuan berkuatkuasa 13 Ogos $1933 .{ }^{18}$ Selain itu, MMN juga telah meluluskan pelantikan F. Robinson sebagai Penasihat Undang-undang dan Hakim Mahkamah Besar dalam mesyuaratnya pada 12 Jun $1924 .{ }^{19}$

Di samping menetapkan pengisian jawatan bagi pegawai Eropah dalam pentadbiran, MMN juga berkuasa melucutkan jawatan tersebut sekiranya tidak diperlukan. Ini dapat dilihat dalam kes H. M. Simpson apabila MMN pada 26 Mei 1924 telah memutuskan bahawa beliau akan diambil bagi mengisi jawatan Penolong Jurutera sementara dengan gaji sebanyak $\$ 400$ sebulan. Dalam hal ini, MMN telah menetapkan bahawa sekiranya perkhidmatan beliau tidak diperlukan lagi, maka satu notis penamatan perkhidmatan akan diberikan. Begitu juga jika beliau hendak meletakkan jawatan, perlulah terlebih dahulu menghantar notis sebulan awal kepada kerajaan. ${ }^{20} \mathrm{Hal}$ ini membuktikan bahawa MMN berhak dalam hal ehwal pelucutan jawatan pegawai Eropah sekiranya perkhidmatan mereka tidak diperlukan lagi dan ini adalah selaras dengan syarat yang dikemukakan oleh Tunku Ibrahim sebelum Perjanjian 1923 ditandatangani.

Selain menetapkan pelantikan pegawai Eropah dalam pentadbiran, sebarang urusan pertukaran para pegawai juga turut dirujuk kepada MMN. Sebagai contoh, Tunku Zainal Rashid yang sebelum ini menjadi Penguasa Monopoli telah ditukarkan menjadi majistret di Mahkamah Kecil Alor Star dengan tempoh percubaan selama setahun setelah diluluskan oleh MMN. Begitu juga dalam hal Che Abdul Manaff Sheriff yang sebelum ini bertugas di Mahkamah Besar pula ditukarkan menjadi Penguasa Monopoli dengan tempoh percubaan selama setahun. Manakala Syed Ali yang sebelum ini menjadi Penolong Ketua Pejabat Tanah ditukarkan secara sementara menjadi Pemangku Sheriff Mahkamah Tinggi. ${ }^{21}$

MMN Kedah juga berkuasa meluluskan perkara-perkara berkaitan pelantikan dan kenaikan pangkat bagi pegawai-pegawai tempatan. Dalam fungsi ini, MMN Kedah sedaya upaya cuba mengisi jawatan kosong dengan mengambil anak jati Melayu Kedah. Apabila wujudnya beberapa kekosongan jawatan, MMN akan cuba memenuhi jawatan tersebut dengan meneliti permohonan yang dibuat oleh orang Melayu terlebih dahulu. Dalam mesyuarat MMN pada 26 Jun 1924 misalnya, ada dibincangkan berkaitan permohonan daripada Mohamed bin Abu Bakar yang merupakan anak jati Melayu Kedah untuk menjawat jawatan dalam perkhidmatan awam Kedah. Setelah dibincangkan, ahli-ahli MMN sebulat suara telah memutuskan bahawa beliau akan diterima masuk ke dalam perkhidmatan awam Kedah. ${ }^{22}$ Begitu juga dengan hal ehwal kenaikan pangkat orang Melayu dalam pentadbiran 
Kedah turut dirujuk kepada MMN untuk diputuskan. Pada tahun 1940 misalnya, Presiden MMN telah menaikkan pangkat Wan Osman bin Wan Ali yang sebelum ini menjawat jawatan Ketua Inspektor menjadi Penolong Pesuruhjaya Polis Melayu Kedah bagi menggantikan Osman bin Mohamad yang telah meninggal dunia. ${ }^{23}$ Jelas dapat dilihat bahawa MMN cuba memastikan penjawat jawatan dalam pentadbiran adalah terdiri daripada orang Melayu Kedah.

Perkara berkaitan pengisian jawatan dalam pentadbiran Kedah sememangnya menjadi satu perkara yang sangat dititikberatkan dalam sistem pentadbiran Kedah. Malah perkara itu akan turut mendapat kritikan dan teguran sekiranya tidak dirujuk kepada MMN. Ini dibuktikan pada tahun 1932 apabila satu surat pekeliling telah dikeluarkan oleh Setiausaha Kerajaan Kedah kepada kesemua ketuaketua jabatan di Kedah berkaitan pengambilan kakitangan di jabatan masing-masing. Surat pekeliling ini memaklumkan bahawa setiap Ketua Jabatan di Kedah yang mahu mengisi jawatan kosong di jabatannya perlulah terlebih dahulu merujuk perkara tersebut kepada MMN. Ini disebabkan terdapat laporan bahawa kekosongan jawatan di sesetengah jabatan telah diisi tanpa merujuk kepada senarai pendaftaran yang disimpan dalam MMN ${ }^{24}$ Dalam hal ini, telah ditetapkan peraturan bahawa calon yang hendak menjawat jawatan dalam perkhidmatan kerajaan perlulah mendaftarkan namanya terlebih dahulu di Pejabat Pelajaran dan nama calon inilah yang akan dirujuk oleh MMN apabila mahu mengisi kekosongan jawatan yang wujud di sesuatu jabatan.

Menurut pekeliling tersebut, pelantikan pegawai masih kekal di tangan ketua-ketua jabatan dan kerajaan. Namun, Penguasa Pelajaran akan memastikan bahawa calon tersebut adalah terdiri daripada orang Melayu dan dilahirkan di Kedah. Ketua-ketua jabatan masih lagi akan diminta untuk menemuduga calon dan membuat perakuan kepada kerajaan. Walau bagaimanapun, nama calon yang sesuai hanya akan diambil dan dirujuk daripada senarai pendaftaran yang sedia ada. Hanya nama mereka yang telah didaftarkan di Pejabat Pelajaran sahaja akan dipertimbangkan ke jawatan-jawatan yang hendak diisi. Dalam hal ini, Pejabat Pelajaran telah dibekalkan dengan nama-nama calon yang didaftarkan bagi mengisi jawatan-jawatan perkhidmatan kerajaan Kedah. Jika terdapat nama atau calon lain yang telah dicadangkan yang tiada dalam senarai daftar di Pejabat Pelajaran, maka Ketua Jabatan perlulah terlebih dahulu menghantar nama calon tersebut kepada Penguasa Pelajaran bagi melaporkan pencapaian akademik dan kelakuan calon semasa bersekolah untuk dipertimbangkan ke jawatan-jawatan kosong dalam jabatan-jabatan pentadbiran di Kedah. ${ }^{25}$ 
Kaedah ini adalah semata-mata mahu memastikan calon-calon yang diambil dalam perkhidmatan Kedah adalah ditapis sepenuhnya sebelum diserap ke dalam jawatan-jawatan penting dalam pentadbiran Kedah. Ini merupakan satu langkah bagi memastikan MMN akan tetap dirujuk sebelum sesuatu pengisian jawatan dibuat. Ini disebabkan apabila wujudnya jawatan-jawatan kosong, rujukan perlulah dibuat terlebih dahulu kepada MMN bagi mengisi jawatan tersebut. Hal ini secara langsung memberi peluang kepada $\mathrm{MMN}$ untuk memilih caloncalon bersesuaian yang terdiri daripada orang Melayu dan anak jati negeri Kedah. Dengan cara ini, keperibadian Kedah sebagai negeri Melayu akan dapat dipertahankan dan calon-calon yang dipertimbangkan sudah semestinya adalah dalam kalangan orang Melayu yang dilahirkan di Kedah.

Sungguhpun pekeliling telah dikeluarkan kepada kesemua ketuaketua jabatan, masih terdapat di antara mereka yang tidak mematuhinya. Dalam satu surat kepada kerajaan Kedah pada tahun 1933 misalnya, Penguasa Pelajaran Kedah telah mengadu bahawa terdapat beberapa kes calon yang diambil bekerja dalam perkhidmatan Kedah tidak didaftarkan namanya di Pejabat Pelajaran. Sebagai contoh, Penguasa Monopoli dan Kastam telah mengambil seorang calon yang dikenali sebagai Mustafa bin Haji Ahmad untuk bekerja di jabatan tersebut walaupun namanya langsung tidak didaftarkan di Pejabat Pelajaran. Meskipun Penguasa Monopoli dan Kastam telah dibekalkan dengan senarai nama calon-calon untuk jawatan pegawai, namun beliau tetap memilih Mustafa untuk menjawat jawatan tersebut tanpa merujuk kepada Penguasa Pelajaran terlebih dahulu. Begitu juga kes yang melibatkan pelantikan Syed Ali bin Syed Salleh sebagai suboverseer (pengawas/mandur) oleh Jurutera Eksekutif di utara Kedah. Nama Syed Ali seperti juga dengan nama Mustafa didapati tidak didaftarkan di Pejabat Pelajaran dan tidak dirujuk namanya kepada Penguasa Pelajaran. ${ }^{26}$

Di samping mempunyai kuasa dalam memutuskan pengisian jawatan dalam pentadbiran, perkara berkaitan kelulusan cuti panjang kepada pegawai Kedah sama ada pegawai tempatan mahupun pegawai Eropah juga akan dirujuk kepada MMN. Dalam mesyuarat MMN misalnya, perkara berkaitan cuti yang dipohon oleh para pegawai akan dibincangkan dan diputuskan oleh MMN sama ada diluluskan ataupun tidak. Sebagai contoh, Jurutera Negeri telah memohon kepada MMN agar meluluskan cuti sakit kepada F. C. D. La Brooy, Pembantu Kewangan Jabatan Kerja Raya selama 31 hari dan perkara ini telah diluluskan oleh MMN dalam mesyuaratnya pada 20 Oktober 1924. Selain meluluskan cuti kepada pegawai Eropah, MMN juga turut 
meluluskan cuti kepada pegawai tempatan. Dalam mesyuarat MMN pada 20 Oktober 1924 misalnya, MMN telah meluluskan cuti sakit kepada Matt Noh bin Matt (Demacator) selama 49 hari dengan gaji dan 31 hari tanpa gaji. ${ }^{27}$ MMN juga turut meluluskan cuti rehat selama sebulan kepada Tunku Kassim, Penguasa Monopoli dan Kastam. ${ }^{28}$

MMN bukan sahaja meluluskan cuti kepada para pegawai Eropah malah turut menetapkan calon bagi pegawai sementara yang akan dilantik untuk menggantikan pegawai yang sedang bercuti. Perkara berkaitan pelantikan pegawai sementara ini juga akan diputuskan dalam mesyuarat MMN yang bersidang seminggu sekali. Jika seseorang pegawai Eropah itu bercuti, maka beliau akan digantikan sementara oleh pegawai yang dipinjamkan daripada NNMB sehinggalah pegawai asalnya pulang daripada bercuti. Sebagai contoh J. J. Fleury, Doktor Veterinar Negeri yang bercuti pada tahun 1925 telah digantikan oleh $\mathrm{R}$. Macgregor yang dipinjamkan daripada kerajaan NNMB. ${ }^{29}$ MMN dalam mesyuarat pada 25 September 1924 juga telah meluluskan cuti rehat kepada E. A. G. Stuart, Penguasa Pelajaran Kedah dan melantik Major J. B. Neilson bagi menggantikan beliau. ${ }^{30}$ Begitu juga dengan permohonan cuti rehat oleh $\mathrm{H}$. H. Corbon, Penolong Penguasa Ukur dan Sukat yang telah diluluskan oleh MMN selama tujuh bulan 29 hari. Dengan ketiadaan H. H. Corbon, beliau akan digantikan sementara oleh J. N. Read. ${ }^{31}$

Selain itu, perkara berkaitan gaji pegawai Eropah turut dibincangkan dalam MMN. Sebagai contoh, gaji Penguasa Workshop iaitu R. Sloane telah dibincangkan dalam mesyuarat MMN pada 19 Jun 1924. MMN telah membenarkan pelantikan beliau sebagai Penguasa Workshop dengan gaji sebanyak $\$ 300$ sebulan dan akan dinaikkan sebanyak $\$ 25$ setahun dengan mendapat elaun rumah. ${ }^{32}$ Selain itu, Penguasa Jabatan Ukur juga telah merujuk kepada MMN untuk mengambil W. P. Aylward menjadi Penolong Penguasa Sukat dengan gaji $\$ 400$ sebulan berkuatkuasa 18 Ogos 1924 dan hal ini telah dipersetujui oleh MMN. ${ }^{33}$

Secara langsung hal ini menunjukkan bahawa perkara penting berkaitan dengan pegawai Eropah seperti pelantikan, kenaikan pangkat, pertukaran dan penempatan pegawai, cuti dan gaji perlu dirujuk kepada MMN. Berdasarkan bukti yang diketengahkan, jelas di sini bahawa syarat Tunku Ibrahim menetapkan bahawa pegawai tadbir British yang hendak dihantar ke Kedah perlulah mendapat kelulusan daripada MMN dan bukannya Penasihat British telah diikuti dalam pentadbiran Kedah. Walaupun Penasihat British merupakan ahli dalam MMN, namun yang lebih penting di sini, sesuatu keputusan itu tidak boleh dibuat atas kapasiti Penasihat British itu sendiri tetapi 
perlu dibuat dalam MMN yang dipengerusikan oleh Presiden MMN. Ini membawa maksud Penasihat British tidak boleh membuat keputusan seperti mana yang dilakukan oleh residen-residen British di NNMB.

Sungguhpun dalam syarat yang dikemukakan oleh Tunku Ibrahim ada menyatakan bahawa pengambilan kakitangan dalam pentadbiran Kedah hendaklah dirujuk kepada Pemangku Raja dan MMN, namun terdapat juga beberapa kes apabila MMN yang diketuai oleh Tunku Ibrahim turut menerima cadangan daripada Penasihat British berkaitan pengisian jawatan dalam pentadbiran. Penasihat British misalnya pernah mencadangkan kepada MMN agar diambil S. N. Samy menjadi Penguasa Jabatan Percetakan dan menjalani tempoh percubaan selama 12 bulan dengan gaji sebanyak $\$ 300$ sebulan. Cadangan ini telah diterima oleh MMN tanpa sebarang bantahan. ${ }^{34}$ Hal ini disebabkan cadangan tersebut tidak menggugat kedudukan perjawatan orang Melayu dalam pentadbiran Kedah.

Dalam situasi ini, dapat dilihat MMN yang dikuasai oleh orang Melayu dari segi keanggotaannya telah mampu mempertahankan kedudukan orang Melayu dalam pentadbiran Kedah. Keanggotaan MMN Kedah yang dikhaskan kepada orang Melayu telah memberi kelebihan kepada perjalanan dan fungsi MMN itu sendiri dalam menentukan hala tuju pentadbiran Kedah. Dengan kuasa yang ada pada MMN dalam memilih bakal pentadbir yang terdiri daripada orang Melayu secara langsung telah menjadikan MMN sebuah badan yang dapat mengawal penguasaan British dalam perjalanan pentadbiran Kedah. Malahan bakal pegawai Eropah yang hendak berkhidmat juga perlu dirujuk kepada MMN dan ini memberi kesempatan kepada MMN sendiri untuk mengawal sama ada dari segi jumlah pegawai British yang dihantar berkhidmat di Kedah mahupun dapat mengawal persaingan antara pihak British dengan orang Melayu.

\section{Pemakaian Pakaian Seragam Oleh Pegawai Melayu dan Eropah}

Berkaitan dengan aspek pemakaian pakaian seragam Kedah, telah diwujudkan satu peraturan pemakaian pakaian seragam Kedah yang perlu dituruti oleh semua pegawai Kedah termasuklah pegawai Eropah yang berkhidmat di Kedah. Warna pakaian seragam bagi pegawaipegawai di Kedah ialah putih dan perlu dipakai oleh pegawai Kelas I hingga Kelas IV. ${ }^{35}$ Pegawai Eropah seperti juga pegawai tempatan telah ditetapkan memakai paḱaian seragam Kedah. 
Perkara mengenai pemakaian pakaian seragam oleh pegawai Eropah turut dibincangkan dalam MMN. Dalam mesyuarat MMN pada 31 Januari 1924 misalnya, turut dibincangkan berkaitan pakaian seragam yang perlu dipakai oleh seorang Doktor Veterinar Negeri, J. J. Fleury. Dalam mesyuarat ini, MMN telah menetapkan bahawa beliau perlu memakai pakaian seragam Kelas II selama mana beliau menjawat jawatan tersebut manakala bagi penjawat jawatan selepas beliau, akan ditetapkan memakai pakaian seragam Kelas III. ${ }^{36}$ Ini menunjukkan bahawa aspek pemakaian seragam bagi pegawai Eropah turut dititikberatkan oleh MMN. Aspek ini juga merupakan salah satu syarat penting yang diutarakan Tunku Ibrahim iaitu pegawai Melayu dan Eropah adalah setaraf dan pegawai Eropah dikehendaki memakai pakaian seragam Kedah. Pakaian seragam ini juga dilihat sebagai satu cara untuk mengekalkan identiti negeri Kedah dan juga menandakan taraf persamaan yang wujud antara pegawai tempatan dan Eropah.

\section{Penghantaran Pelajar Melayu ke Luar Negeri}

Selain itu, perkara berkaitan penghantaran pelajar ke luar negeri merupakan salah satu lagi syarat penting seperti mana yang ditetapkan oleh Tunku Ibrahim sebelum Perjanjian 1923 dimeterai. Seperti juga syarat-syarat berkaitan pelantikan pegawai dalam perkhidmatan awam Kedah, syarat penghantaran pelajar Melayu Kedah ke luar negeri turut dipenuhi. Hal ini dapat dibuktikan apabila isu berkaitan penghantaran pelajar ke luar negeri turut dibincangkan secara panjang lebar dalam MMN Kedah. Dalam mesyuarat MMN pada 14 Ogos 1924 misalnya ada dibincangkan berkaitan seorang pelajar Melayu Kedah yang dikenali sebagai Mustapha Osman yang melanjutkan pelajaran ke sebuah universiti di Hong Kong. Pelajar ini dihantar melanjutkan pelajaran dalam bidang perubatan dengan mendapat pembiayaan sepenuhnya daripada kerajaan negeri Kedah. Dalam mesyuarat MMN tersebut, isu yang dibincangkan adalah berkaitan dengan cadangan pihak universiti yang berpendapat bahawa Mustapha Osman perlu melanjutkan pelajarannya selama setahun lagi. Dalam hal ini, MMN telah memberikan persetujuan terhadap perkara tersebut namun menetapkan bahawa beliau perlu berkhidmat dengan kerajaan negeri Kedah sekembalinya dari Hong Kong. ${ }^{37}$

Di samping itu, kerajaan Kedah juga telah mewujudkan program pendidikan pelajar diraja yang membolehkan penghantaran beberapa orang kerabat diraja melanjutkan pelajaran ke England. Pada tahun 1925 misalnya, seramai lapan orang berketurunan Tunku telah dihantar ke England dan diberi jaminan kerja selepas kembalinya mereka ke tanah air. Mereka ini termasuklah lima orang putera Sultan Abdul 
Hamid Halim Shah dan tiga orang putera Pemangku Raja, Tunku Ibrahim. Walau bagaimanapun, dasar ini telah diubah pada 1930-an semasa Mohamed Sheriff Osman menjadi Setiausaha Kerajaan. Beliau telah membuka pintu kepada rakyat biasa untuk dihantar melanjutkan pelajaran ke luar negeri. Sehingga meletusnya Perang Dunia Kedua, terdapat 16 orang pegawai Melayu di Kedah yang mempunyai kelulusan dari pusat pengajian tinggi di England dalam pelbagai bidang. ${ }^{38}$

Ini secara langsung menunjukkan bahawa kerajaan Kedah telah menghantar dan membiayai para pelajar Melayu untuk melanjutkan pelajaran ke luar negeri dalam bidang tertentu. Malah, kerajaan berharap agar golongan pelajar ini akan kembali dan berkhidmat dengan Kedah apabila tamatnya pengajian mereka kelak. Penghantaran para pelajar Melayu ini juga adalah sebagai satu langkah untuk mendedahkan mereka dengan pengalaman dan ilmu-ilmu baru yang akan diperoleh mereka semasa menuntut di luar negeri dan dengan itu dapat diaplikasikan dalam pentadbiran Kedah sendiri tanpa mengharapkan bantuan asing.

Di samping menghantar anak-anak Melayu Kedah ke luar negeri, anak-anak Melayu kelahiran Kedah juga turut dihantar ke institusiinstitusi pengajian tempatan. Sebagai contoh, terdapat pelajar yang dihantar ke sekolah-sekolah teknikal bagi menjalani kursus dan latihan. Dalam Jabatan Ukur dan Sukat yang sememangnya memerlukan kemahiran teknikal, beberapa pelajar yang mempunyai pendidikan tinggi terutamanya dalam matematik telah direkrut untuk menjadi pelatih dan dihantar ke sekolah teknikal di Kuala Lumpur untuk tempoh dua tahun dan diberikan gaji $\$ 50$ sebulan. ${ }^{39}$

Nama-nama calon yang akan direkrut biasanya akan dikemukakan oleh Penguasa Ukur. Pada tahun 1932 misalnya, Penguasa Ukur dan Sukat telah mengemukakan empat nama kepada kerajaan Kedah bagi dipertimbangkan sebagai pelatih untuk Pejabat Sukat. Mereka ialah Mohd. Yunan bin Ahmad, Osman bin Matt, Yusoff bin Hashim dan Abdul Rashid bin Abdul Hamid. Kesemua mereka yang dicadangkan ini terdiri daripada anak jati Melayu Kedah. Mohd Yunan bin Ahmad misalnya dilahirkan di Kulim dan mendapat pendidikan di sekolah Melayu di Kulim dan Penang Free School sementara Yusoff bin Hashim pula dilahirkan di Bandar Bharu dan mendapat pendidikan di sekolah Inggeris di Alor Setar. ${ }^{40}$

Keempat-empat calon ini akan menjalani kursus selama dua tahun dan akan menduduki satu peperiksaan yang akan menentukan sama ada mereka layak atau tidak untuk berkhidmat di dalam Pejabat Sukat. Jika mereka gagal dalam peperiksaan, perkhidmatan mereka akan ditamatkan dengan diberikan sebulan notis. Walau bagaimanapun, 
dalam kes ini terdapat beberapa pengecualian. Dalam surat Penguasa Sukat kepada Setiausaha Kerajaan, telah dilaporkan bahawa selepas menjalani kursus selama dua tahun dan menduduki peperiksaan, hanya Osman bin Matt sahaja yang lulus dalam peperiksaan khas manakala dua lagi calon iaitu Mohd Yunan bin Ahmad dan Yusoff bin Hashim telah gagal dalam peperiksaan tersebut. Jika mengikut peraturan yang sedia ada, perkhidmatan mereka akan ditamatkan disebabkan kegagalan mereka dalam peperiksaan tersebut. Walau bagaimanapun, mereka telah diberikan peluang kedua disebabkan kedua-duanya menunjukkan prestasi kerja yang memuaskan. Untuk itu, mereka dikehendaki menjalani kursus tambahan selama setahun lagi di sekolah teknikal tersebut dan perlu lulus satu peperiksaan yang dikenali sebagai Bar Test. ${ }^{41}$

Dalam hal ini, didapati bahawa faktor prestasi seseorang pelatih yang akan menentukan sama ada mereka akan terus dikekalkan atau ditamatkan perkhidmatan mereka. Ini dapat dibuktikan dalam satu kes yang membabitkan Abdul Rashid bin Abdul Hamid dan Che Din bin Junid. Dalam hal ini, kedua-dua mereka telah gagal dalam Intermediate Exam yang telah diadakan. Walaupun Abdul Rashid telah gagal dalam peperiksaan tersebut, Penguasa Ukur masih berpendapat bahawa beliau telah menunjukkan prestasi kerja yang sangat memuaskan semasa menjalani kursus dan mencadangkan agar beliau dikekalkan sebagai Junior Technical Subordinate. Beliau akan mendapat gaji sebanyak $\$ 50$ dan akan kekal pada tangga gaji tersebut tanpa sebarang kenaikan sehinggalah beliau lulus dalam Junior Technical Bar Test. Namun berbeza pula situasi yang dihadapi oleh Che Din apabila Penguasa Sukat sendiri tidak berpuas hati dengan prestasi yang ditunjukkan beliau. Beliau tidak dikekalkan sebagai Junior Technical Subordinate sebaliknya telah diberi notis sebulan penamatan perkhidmatan ekoran kegagalannya dalam peperiksaan. ${ }^{42}$

Ini merupakan salah satu contoh pengambilan pelatih-pelatih oleh Pejabat Sukat dilakukan dengan tegas dan bukannya secara sambil lewa. Meskipun pelatih tersebut terdiri daripada orang Melayu Kedah sendiri, namun itu bukanlah merupakan satu jaminan bahawa mereka pasti diterima masuk dalam pentadbiran Kedah. Mereka sebaliknya seharusnya mempunyai kelayakan dan prestasi yang setaraf dengan pegawai British yang lain supaya mereka kelak akan mampu bersaing sama rata dan tidak jauh ketinggalan dalam persaingan tersebut. Dalam hal ini, seseorang pelatih tersebut akan diberikan tugas setelah mereka tamat menjalani kursus dan lulus dalam satu peperiksaan khas. Para pelatih yang paling berkemampuan akan diberi kepercayaan untuk mengendalikan kerja-kerja ukur di daerah-daerah. Pengendalian 
tugas-tugas seperti ini telah membantu menyediakan para pelatih Melayu dengan ilmu dan pengalaman yang berguna dan sekaligus menjadi persediaan kepada mereka untuk melakukan tugas-tugas teknikal yang lebih mencabar pada masa hadapan.

\section{Pengekalan Setiausaha Kerajaan dan Ketua Hakim Melayu Dalam MMN}

Satu lagi syarat penting yang dikemukakan oleh Tunku Ibrahim adalah berkaitan dengan jawatan Setiausaha Kerajaan dan Ketua Hakim Melayu sebagai ahli MMN. Syarat penting ini nampaknya turut diperakui pihak British apabila keanggotaan kedua-dua jawatan tersebut tetap dikekalkan di dalam MMN. Jawatan Setiausaha Kerajaan misalnya tidak pernah ketinggalan disenaraikan sebagai ahli dalam MMN. Bermula dengan penjawat pertamanya iaitu Che Mohamad Ariffin bin Dato' Kerani Mohammad Arshad sehinggalah kepada Sheriff Osman yang menjawat jawatan tersebut dari 1931-1948, penjawat jawatan ini kekal menjadi ahli dalam MMN.

Setiausaha Kerajaan adalah jawatan tertinggi dalam pentadbiran awam dan merupakan pegawai pentadbir yang paling penting dalam kerajaan Kedah. Sebelum jawatan ini diwujudkan, jawatan yang dianggap setaraf dengannya ialah Kerani Rahsia Sultan. Setiausaha Kerajaan sebelum Perang Dunia Kedua sangat penting dan dianggap setaraf jawatannya dengan Menteri Besar selepas $1948 .{ }^{43}$ Antara Setiausaha Kerajaan yang terkenal ialah Mohamed Sheriff Osman yang menjawat jawatan sebagai Setiausaha Kerajaan pada 18 Mei 1931. Beliau dikenali sebagai tokoh yang berperanan penting dalam pentadbiran Kedah. Pelantikan Mohamed Sheriff Osman sebagai Setiausaha Kerajaan yang merupakan jawatan tertinggi dalam sistem birokrasi adalah satu perubahan yang penting dalam sistem perjawatan Kedah apabila sebelum ini, jawatan tersebut hanya dimonopoli oleh golongan bangsawan. Hal ini dapat dikaitkan dengan hubungan rapat keluarga Sheriff Osman dengan keluarga diraja Kedah.4 Menurut Khuzaini Khalid dalam tulisannya, Sheriff Osman dikatakan gemar melaksanakan tugas mengikut telunjuk penjajah. Segala arahan dan nasihat daripada Penasihat British diterima beliau dan dilaksanakan tanpa sebarang bantahan. Maka, tidak hairanlah sekiranya beliau mendapat kerjasama daripada pegawai-pegawai British ketika itu. ${ }^{45}$

Semasa Sheriff Osman memegang jawatan Setiausaha Kerajaan, beliau memainkan peranan yang penting dalam Pejabat Setiausaha Kerajaan. Semua dasar dan arahan kerajaan yang datang dari MMN akan disalurkan ke bahagian-bahagian lain melalui Pejabat Setiausaha Kerajaan yang diketuai oleh Sheriff Osman. Begitu juga maklumat 
yang diterima dari bawah yang hendak disampaikan kepada MMN perlulah dibuat melalui pejabat ini terlebih dahulu. Dalam hal ini, Sheriff Osman akan meneliti terlebih dahulu isi kandungan fail yang hendak disampaikan dan akan mencatat arahan serta komennya pada fail tersebut. Setiap kes yang dirujuk akan diteliti dan diatasi. Walau bagaimanapun, ini tidak bermakna bahawa semua keputusan pentadbiran dibuat oleh Sheriff Osman di Pejabat Setiausaha sahaja kerana jika terdapat perkara yang melibatkan kewangan misalnya, maka Pegawai Kewangan Negeri dan Perbendaharaan akan dirujuk. Jika perkara ini melibatkan undang-undang, pandangan Penasihat Undang-undang akan diperlukan. Namun, jika sesuatu perkara itu melibatkan persoalan yang lebih besar, maka kes itu akan dirujuk bagi mendapatkan keputusan muktamad daripada MMN. ${ }^{46}$

Segala urusan surat-menyurat juga diuruskan oleh Sheriff Osman dan Penolong Penasihat British. ${ }^{47}$ Pada mulanya, kesemua surat ketua jabatan akan dihantar terus kepada Penasihat British. Walau bagaimanapun, berlaku beberapa perubahan apabila surat-surat kini tidak lagi dihantar terus kepada Penasihat British sebaliknya telah ditetapkan hanya Setiausaha Kerajaan sahaja yang akan menulis kepada Penasihat British untuk mendapatkan nasihat. Manakala Penolong Setiausaha Kerajaan akan menulis surat kepada Penolong Penasihat British. ${ }^{48}$ Sistem ini adalah berbeza dengan sistem di NNMB apabila residen sendiri yang menguruskan semua urusan penting melalui satu sekretariat di bawah pengawasan seorang setiausaha kepada residen. ${ }^{49}$ Antara surat-surat dan fail-fail yang perlu diteliti oleh Sheriff Osman termasuklah fail-fail berkaitan pelantikan, pertukaran dan peperiksaan bagi pegawai-pegawai Melayu, surat-surat kepada ketua jabatan dan laporan prestasi kerja pegawai Melayu. Sebagai contoh, pada tahun 1941, terdapat beberapa permohonan daripada beberapa pegawai bawahan dan kerani rendah untuk menduduki peperiksaan kerani yang perlu diteliti oleh Sheriff Osman sebagai Setiausaha Kerajaan pada ketika itu. Antara calon yang dipertimbangkan dalam permohonan itu termasuklah individu yang dikenali sebagai Mohd Darus bin Mahmud, Jamaludin bin Haji Husein, Mahmud bin Abdullah dan Mustafa bin Ismail. Untuk menduduki peperiksaan ini, kesemua calon perlulah menghantar permohonan mereka kepada ketua di jabatan masing-masing. Hanya setelah diterima permohonan tersebut, barulah ketua-ketua jabatan akan mengajukannya kepada Setiausaha Kerajaan untuk dipertimbangkan permohonan mereka. Dalam hal ini, ketua-ketua jabatan akan memberi beberapa cadangan dan komen terhadap calon. ${ }^{50}$ Walau bagaimanapun, hanya Setiausaha Kerajaan yang mempunyai kuasa dalam menentukan sama ada calon tersebut dibenarkan untuk menduduki peperiksaan ataupun tidak. 
Ini dapat dilihat dalam permohonan Mustaffa Ismail daripada Pejabat Tanah Kedah yang mahu menduduki peperiksaan kerani. Permohonan beliau telah diajukan oleh Penasihat Tanah Kedah kepada Setiausaha Kerajaan. Dalam surat kepada Setiausaha Kerajaan, Penasihat Tanah Kedah menyatakan bahawa Mustaffa seorang yang rajin dan memohon agar kerajaan memberi pertimbangan yang sewajarnya terhadap permohonannya. Walau bagaimanapun, permohonan tersebut tidak dibenarkan disebabkan tiada kekosongan tempat untuknya. Begitu juga dengan permohonan daripada Jamaludin bin Haji Hussein yang disokong kuat oleh Ketua Pejabat Tanah Baling apabila beliau mencadangkan agar kerajaan memberi peluang kepada calon tersebut yang pada pendapatnya adalah seorang yang rajin. Namun, permohonan ini juga turut ditolak oleh Setiausaha Kerajaan. ${ }^{51}$

Berbeza pula dengan permohonan daripada Mohd Darus bin Mahmud yang telah diajukan permohonannya oleh Pegawai Daerah Yan kepada Setiausaha Kerajaan untuk dipertimbangkan. Sheriff Osman dalam suratnya kepada Pegawai Daerah Yan telah memberi persetujuan terhadap permohonan Mohd Darus untuk menduduki peperiksaan Kerani Inggeris II. Dalam hal ini didapati bahawa kuasa untuk menentukan permohonan sesuatu calon adalah tertakluk di bawah bidang kuasa Setiausaha Kerajaan dan bukannya ketua-ketua jabatan. Ketua jabatan hanya sekadar mengajukan permohonan calon sementara keputusan muktamad adalah terletak di tangan Setiausaha Kerajaan.

Di samping menguruskan surat-surat dan fail-fail kerajaan, Sheriff Osman turut menerima laporan-laporan tahunan daripada ketua-ketua jabatan di Kedah. Beliau akan meneliti setiap laporan tahunan yang diterima dan akan membuat sebarang cadangan dan komen berkaitan laporan tersebut. Malah beliau juga memastikan agar setiap ketua jabatan menghantar laporan tahunan dengan menghantar surat peringatan atau memo kepada setiap ketua jabatan agar laporan tahunan dihantar dengan kadar segera dan tepat pada masanya. ${ }^{52}$ Selain itu, beliau juga turut menerima laporan daripada ketua-ketua jabatan berkaitan prestasi pegawai-pegawai Melayu. Pada tahun 1932 misalnya, Sheriff Osman turut menerima laporan daripada Ketua Majistret Alor Setar berkaitan prestasi seorang kerani Melayu yang dikenali sebagai Ibrahim Abdul Ghani. Beliau dikatakan tidak menjalankan tugas dengan baik dan bekerja secara lewa. ${ }^{53}$

Tugas Sheriff Osman sebagai Setiausaha Kerajaan dalam pentadbiran dilihat sangat luas. Malah beliau pernah diberi kepercayaan menjadi Pemangku Presiden dalam MMN semasa ketiadaan Tunku Badlishah (Presiden MMN, 1937-1942) yang mengadakan lawatan ke Cameron Higlands pada tahun 1941. Tunku Badlishah sendiri yang memilih dan melantik Sheriff Osman untuk 
mempengerusikan mesyuarat MMN dan membenarkan Sheriff Osman untuk menandatangani semua surat dan dokumen penting bagi pihaknya semasa ketiadaan baginda. ${ }^{54}$ Meskipun Sheriff Osman sendiri merupakan ahli dalam MMN pada ketika itu, namun dalam keadaan tersebut, Presiden MMN tidak dapat mempengerusikan mesyuarat atas sebab-sebab tertentu, maka Presiden sendiri yang akan melantik pemangku bagi jawatannya dalam kalangan ahli-ahli MMN sendiri. Jadi, dalam hal ini dapat dilihat bahawa Sheriff Osman semasa ketiadaan Presiden MMN telah memegang dua keahlian dalam MMN iaitu sebagai Setiausaha Kerajaan dan juga sebagai Pemangku Presiden MMN. Atas kepentingan jawatan ini, maka tidak hairanlah jika Tunku Ibrahim, selaku Pemangku Raja Kedah meletakkan syarat bahawa Setiausaha Kerajaan perlulah menjadi ahli MMN sebelum Perjanjian 1923 ditandatangani. Usaha mengekalkan Setiausaha Kerajaan ini dilihat sebagai satu cara untuk mengawal pentadbiran Kedah memandangkan jawatan tersebut merupakan perjawatan Melayu yang sangat berpengalaman.

Di samping pengekalan jawatan Setiausaha Kerajaan, jawatan bagi Ketua Hakim Melayu juga turut dikekalkan sebagai ahli dalam MMN dalam tempoh selepas Perjanjian 1923 ditandatangani. Ini dapat dilihat dalam setiap minit mesyuarat MMN selepas tahun 1923 apabila Ketua Hakim Melayu turut disenaraikan sebagai ahli MMN dan turut menghadiri mesyuarat MMN yang telah diadakan. Malah Ketua Hakim Melayu yang pertama iaitu Syed Hassan Barakbah telah dikekalkan keanggotaannya sebagai ahli dalam MMN sehinggalah beliau digantikan oleh Syed Mansur al-Jafri pada tahun 1926. Cadangan untuk melantik Syed Mansur al-Jafri sebagai Ketua Hakim Melayu telah dimesyuaratkan dalam MMN pada 13 Mei 1926. Dalam mesyuarat ini, MMN telah bersetuju terhadap pelantikan Syed Mansur al-Jafri sebagai Ketua Hakim Melayu dan juga sebagai ahli dalam MMN. Beliau akan menerima gaji sebanyak $\$ 750$ sebulan serta elaun peribadi sebanyak $\$ 125 .{ }^{55}$

\section{Pengunaan Bahasa Melayu dan Tulisan Jawi Dalam Pentadbiran}

Jika dirujuk kembali artikel ketujuh dalam Perjanjian 1923 berkaitan penggunaan bahasa Melayu dan tulisan Jawi, dapat dilihat bahawa penggunaan kedua-duanya dalam pentadbiran Kedah tetap dikekalkan. Ini jelas dapat dikesan dalam minit-minit mesyuarat pada tempoh selepas Perjanjian 1923 ditandatangani. Sebagai contoh minit mesyuarat MMN Kedah dikeluarkan dalam dua salinan iaitu salinan jawi Melayu dan salinan Rumi Inggeris. Kandungan yang terdapat 
dalam minit tersebut adalah sama, cuma yang membezakannya ialah bahasa dan tulisan. Malah, dalam laporan-laporan yang dikeluarkan oleh ketua-ketua jabatan seperti di Jabatan Pelajaran, Perhutanan, Ukur dan Sukat, Kerja Raya dan jabatan yang lain turut menggunakan bahasa Melayu dan tulisan Jawi. Begitu juga dengan laporan yang dikeluarkan oleh para pegawai daerah seperti di daerah Langkawi, Yan, Kubang Pasu, Kuala Muda, Kulim, Baling, Padang Terap, Bandar Bharu, Krian dan Alor Setar serta surat-surat rasmi antara Pemangku Raja, Setiausaha Kerajaan dan Ketua-ketua Jabatan juga menggunakan bahasa Melayu dan tulisan Jawi. Di samping itu, dalam tempoh selepas 1923 juga menyaksikan penerbitan Warta Kerajaan Kedah dibuat dalam dua versi iaitu dalam bahasa Melayu (Jawi) dan Inggeris. Malah keduadua versi ini telah digabung dan disusun dalam satu jilid yang sama.

\section{Kesimpulan}

Secara keseluruhannya, dapat dilihat bahawa kedudukan orang Melayu dalam pentadbiran Kedah selepas Perjanjian 1923 didapati terjamin. Ini dapat dibuktikan dalam MMN a pabila pemilihan, penempatan dan jawatan calon dalam pentadbiran Kedah ditentukan sendiri oleh MMN yang dikuasai orang Melayu. Malah MMN turut berkuasa dalam aspek pengisian jawatan pegawai Eropah. Sementara itu, bagi mengekalkan identiti Kedah sebagai negeri Melayu, MMN Kedah mengutamakan calon-calon Melayu kelahiran negeri Kedah dalam mengisi jawatanjawatan kosong. Ini adalah selaras dengan syarat Tunku Ibrahim yang mahukan seboleh mungkin jawatan pegawai negeri diberi keutamaan kepada anak jati Melayu Kedah sendiri. Situasi ini dilihat dapat menjamin menjamin kedudukan orang Melayu dalam pentadbiran Kedah. Malah dalam pentadbiran Kedah sendiri, penggunaan bahasa Melayu dan tulisan Jawi yang melambangkan identiti Melayu telah dikekalkan penggunaannya. Kaedah ini secara langsung dapat memastikan penguasaan British di Kedah dapat diminimumkan manakala kedudukan orang Melayu dalam pentadbiran Kedah dapat dipertahankan. Tegasnya, ini membuktikan bahawa syarat-syarat yang telah dikemukakan oleh Tunku Ibrahim sebelum Perjanjian 1923 ditandatangani mampu mempertahankan identiti dan kepentingan perjawatan Melayu dalam pentadbiran Kedah. Dengan kata lain, kedudukan orang Melayu dalam pentadbiran Kedah setelah penglibatan British tidak banyak tergugat malah semakin diperkukuhkan selepas Perjanjian 1923 ditandatangani. 


\section{Nota}

1 Perbincangan konflik pembesar Melayu Kedah dengan W.G. Maxwell, sila rujuk, Sharom Ahmat, Tradition and Change in A Malay State: A Study of the Economic and Political Development of Kedah, 1878-1923, Kuala Lumpur: Art Printing Works Sdn. Bhd., 1984, hlm. 155.

2 Muhammad Isa Othman, Politik Tradisional Kedah, 1681-1942, Kuala Lumpur: Dewan Bahasa dan Pustaka, 1990, hlm. 90 \& 91.

3 Sharom Ahmat, "Sejarah Negeri Dalam Pensejarahan Malaysia: Sejarah Kedah 1842 Hingga 1923 Sebagai Contoh", dalam Konvensyen Sejarah Negeri Kedah, 28 November - 1 Disember 1981, hlm. 9.

4 Muhammad Isa Othman, Politik Tradisional Kedah, 1681-1942, hlm. 9395.

Ibid., hlm. 95.

Ibid.

G. Mohamed Khan, History of Kedah, Penang: Penang Premier Press, 1958, hlm. 138.

$8 \quad$ W. G. Maxwell \& W. S. Gibson (eds.), Treaties and Engagements Affecting the Malay States and Borneo, London: Jas Truscott \& Son Ltd., 1924, hlm. $104 \& 105$.

$9 \quad$ Ibid., hlm. $102 \& 103$.

10 Muhammad Isa Othman, "Majlis Mesyuarat Negeri Kedah: Cabaran Politik dan Pentadbiran Dalam Konteks Kesetiaan dan Kenegerian", dalam Mahani Musa \& Tan Liok Ee, Sorotan Terpilih Dalam Sejarah Malaysia, Pulau Pinang: Universiti Sains Malaysia, 2000, hlm. 88.

11 Ibid., hlm. 91.

12 Sharom Ahmat, Tradition and Change in A Malay State: A Study of the Economic and Political Development of Kedah, 1878-1923, hlm. 171 \& 172.

13 Muhammad Isa Othman, Politik Tradisional Kedah, 1681-1942, hlm. 98

14 Ibid.

15 Ibid.

16 Ibid., hlm. 99.

17 Fail Setiausaha Kerajaan Kedah (SUK.K) 82/1353, Appointment of Mr. G. B. Kellagher, M. C. S. to the Post of European Judge, Kedah.

18 SUK.K 1458/1352, Appointment of Mr. Justice John Christopher Cobbett, Judge, Penang as Judge for the Kedah Court of Appeal.

19 SUK.K 2746/1342, Minutes of Meeting of the State Council Held on 12th June 1924 (9.11.42).

20 SUK.K 2480/1342, Minutes of Meeting of the State Council Held on $26^{\text {th }}$ May 1924 (21.10.42).

21 SUK.K 597/1343, Minutes of Meeting of the State Council Held on 8.9.24 (8.2.43).

22 SUK.K 2744/1342, Minutes of Meeting of the State Council Held on $26^{\text {th }}$ June 1924 (23.11.42).

23 State Council (S. C.) 89/1360, Promotion of Wan Osman bin Wan Ali, Chief Inspector to the Rank of Assistant Commissioner of Police. Wan Osman pada masa itu berumur 41 tahun adalah anak jati Melayu Kedah 
24 SUK.K 307/1349, Issue of a Circular to the Effect Heads of Department Proposing to Fill Up Appointment Should Refer to the State Council For A Waiting List of Applications.

25 Ibid.

26 Ibid.

27 SUK.K 789/1343, Minutes of Meeting of the State Council Held on 20.10.24 (21.3.43).

28 SUK.K $759 / 1343$, Minutes of Meeting of the State Council Held on $2^{\text {nd }}$ October 1924 (3.3.43).

29 Kedah Annual Report, 2 August 1924-21 July 1925.

30 SUK.K 600/1343, Minutes of Meeting of the State Council Held on $25.9 .24(25.2 .43)$.

31 SUK.K 789/1343, Minutes of Meeting of the State Council Held on 20.10.24 (21.3.43).

32 SUK.K 2745/1342, Minutes of Meeting of the State Council Held on $19^{\text {th }}$ June 1924 (16.11.42).

33 SUK.K 600/1343, Minutes of Meeting of the State Council Held on 25.9.24 (25.2.43).

34 SUK.K 2749/1342, Minutes of Meeting of the State Council Held on $15^{\text {th }}$ May 1924 (10.10.42).

35 Mohammad. Isa Othman, Pengalaman Kedah dan Perlis: Zaman Penjajahan British, Kuala Lumpur : Utusan Publications, 2001, hlm. 206.

36 SUK.K 1510/1342, Minutes of Meeting of the State Council Held on 31st January 1924 (23.6.42).

37 SUK.K 396/1343, Minutes of Meeting of the State Council Held on 14.8.24 (13.1.43).

38 Mohammad. Isa Othman, Pengalaman Kedah dan Perlis: Zaman Penjajahan British, hlm. 201.

39 SUK.K 428/51, Appointment of Field Apprentices, Survey Dept. Recommends: Perkara Hendak Ambil Orang-orang Perbuat Kerja Menjadi Pelatih Office Sukat.

40 Ibid.

41 Ibid.

42 SUK.K 556/1351, Cost of Training of Kedah Survey Apprentice of the Technical School, Kuala Lumpur.

43 Mohammad. Isa Othman, Pengalaman Kedah dan Perlis: Zaman Penjajahan British, hlm. 213.

${ }_{44}$ Khuzaini Khalid, 'Peranan Tuan Haji Mohd. Sheriff Osman Dalam Pentadbiran Negeri Kedah, 1931-1954', Pusat Pengajian Ilmu Kemanusiaan, Bahagian Sejarah, Universiti Sains Malaysia, 1986/1987, hlm. 2 \&12.

45 Ibid., hlm. 13

$46 \quad$ Ibid., hlm. 212.

47 Rupert Emerson, A Study in Direct and Indirect Rule, Kuala Lumpur: University of Malaya Press, 1970, hlm. 239.

48 Mohammad. Isa Othman, Pengalaman Kedah dan Perlis: Zaman Penjajahan British, hlm. 251. 
49 Rupert Emerson, A Study in Direct and Indirect Rule, hlm. 239.

50 S. C. $880 / 1360$, Applications From Certains Subordinates and Junior Clerks to Sit for the Clerical Examination.

51 Ibid.

52 SUK. K 802/1351, Reminder to Heads of Department to Send in Annual Reports.

53 SUK. K 250/1351, Report on the Unsatisfactory Work of Ibrahim bin Abdul Ghani, M. III, Lower Court, Alor Setar.

54 S. C. 368/1360, Appoinment of the Hon'ble Haji Md. Sheriff bin Osman C. B. E. as Acting President State Council During the Absence on a Visit of His Highness the Regent to Cameron Highlands.

55 SUK.K, 1974/44, Proposed Appointment of Tuan Syed Mansur Aljaffri as Chief Malay Judge and Member of State Council. 